\title{
SPububaúde
}

ARTIOO ORIGIMAL

\section{Elaboração de hambúrguer de carne bovina com adição de farinha de sorgo (Sorghum Vulgare)}

\section{Preparation of beef burger with addition of sorghum flour (Sorghum Vulgare)}

\section{Ana Beatriz Costa Fernandes ${ }^{\circ}$, Sandriane Pizato ${ }^{10}$ \\ Universidade Estadual de Maringá. Departamento de Engenharia de Alimentos. Umuarama, PR, Brasil.}

\section{E-mail anabcf1@gmail.com}

Como citar: Fernandes, A.B.C., Pizato, S. 2019. Elaboração de hambúrguer de carne bovina com adição de farinha de sorgo (Sorghum Vulgare), 2, aoog. DOI: https://dx.doi.org/10.31533/pubsaude2.a o०g

Recebido: 17 set. 2019.

Revisado e aceito: 28 out. 2019.

Conflito de interesse: OS autores declaram, em relação aos produtos e companhias descritos nesse artigo, não ter interesses associativos, comerciais, de propriedade ou financeiros que representem conflito de interesse.

Licenciamento: Este artigo é publicado na modalidade Acesso Aberto sob a licença Creative Commons Atribuição 4.0 (CC-BY 4.0).
R e s u mo . O hambúrguer é um alimento bastante apreciado e consumido pela população de diversas faixas etárias. No intuito de melhorar a qualidade nutricional, o objetivo do presente estudo foi desenvolver um hambúrguer de carne bovina com adição de diferentes concentrações de farinha de sorgo: 2,$5 ; 5,0 ; 7,5$ e $10 \%$ e avaliar seus atributos nas características físicas, químicas, microbiológicas e sensoriais. Os hambúrgueres apresentaram níveis microbiológicos de acordo com o preconizado pela Legislação Brasileira e valores de $\mathrm{pH}(5,64-5,72)$ adequados para produtos cárneos, estando o produto próprio para o consumo. Os resultados das características de umidade mostraram que o hambúrguer cozido da formulação quatro (F4) obteve maior umidade $(63,02 \%)$ em relação as outras amostras. Nos parâmetros cor $\left(L^{*}, a^{*}\right.$ e $\left.b^{*}\right)$ observou-se que quanto maior a concentração de farinha, mais intensa (escura) a cor do hambúrguer. A análise instrumental da força de cisalhamento mostrou que o acréscimo de farinha de sorgo não afetou significativamente a textura dos hambúrgueres, tendo a formulação 1 uma textura de $1,80 \mathrm{kgf} / \mathrm{s}$ e a formulação 4 uma textura de 1,86 kgf/s. Os valores do cozimento mostraram que os hambúrgueres com maior percentual de farinha de sorgo apresentaram maior capacidade de retenção de umidade $(92,66 \%)$ e com isso maior rendimento $(89,14 \%)$ e um menor encolhimento das amostras com maior quantidade de farinha $(9,48 \%)$ contribuindo para maior suculência. A análise sensorial utilizando a escala hedônica de nove pontos, com 103 consumidores, constatou que todos os atributos avaliados (avaliação global, cor, sabor, textura, intenção de compra) nas 4 formulações apresentadas, apresentaram boa aceitação sensorial e intenção de compra, porém a formulação 2 foi a melhor aceita pelos consumidores. 
P a l avra s-ch ave : aceitabilidade, análises tecnológicas, farinha de sorgo, hambúrguer.

A bstract. The hamburger is a food very appreciated and consumed by the population of diverse age groups. In order to improve the nutritional quality of this meat product the objective is to develop a hamburger with different amounts of sorghum flour: $2.5 ; 5.0 ; 7.5$ and $10 \%$ and indicators of physical, chemical, microbiological and sensory properties. The hamburgers presented microbiological levels according to the one recommended by the Brazilian Legislation and $\mathrm{pH}$ values (5.64-5.72) suitable for meat products, showing that the product is suitable for consumption. The results of the oven humidity characteristics at $105{ }^{\circ} \mathrm{C}$ for 5 hours showed that the cooked hamburger of the F4 formulation obtained a higher humidity (63.02\%) than the other samples. In the parameter color $\left(L^{*}, a^{*}\right.$ and $\left.b^{*}\right)$ it was observed that the higher the concentration of flour, the more intense the color of the hamburger. Instrumental analysis of the shear force showed that the addition of sorghum flour did not significantly affect the texture of the burgers having formulation 1 having a texture of 1.80 $\mathrm{kgf} / \mathrm{s}$ and formulation 4 having a texture of $1.86 \mathrm{kgf} / \mathrm{s}$. The baking values showed that the hamburgers with the highest percentage of sorghum flour had a higher moisture retention capacity (92.66\%), with a higher yield (89.14\%) and a lower shrinkage of the samples with a higher amount of flour (9.48\%) contributing to greater succulence. The sensorial analysis using the nine-point hedonic scale, with 103 consumers, found that all the evaluated attributes (overall evaluation, color, taste, texture, purchase intention) had in the 4 formulations presented, good sensory acceptance and purchase intension, but formulation 2 was the best accepted by consumers.

K e y w o r d s : hamburger; sorghum flour; technological analysis, acceptability.

\section{INTRODUÇÃO}

Hambúrguer é um produto cárneo industrializado muito popular, principalmente devido a sua comercialização por redes fast foods. Para satisfazer o desejo dos consumidores por produtos com sabor e textura da gordura e ao mesmo tempo reduzir as calorias, pesquisadores tem desenvolvido numerosos substitutos de gordura, os quais contribuem com menos calorias nas formulações de alimentos sem alterar o sabor, viscosidade e outras propriedades organolépticas da gordura (Rodrigues, 2008). 
Do ponto de vista tecnológico a adição de farinha de sorgo traz benefícios a alguns produtos pois, apresenta alto teor de fibras (18\%) e compostos bioativos (fenólicos totais, antocianinas, carotenoides, taninos e amido resistente), e baixo teor de lipídeos (1,2\%) (Waniska et al., 2008).

O sorgo (Sorghum vulgare) é um cereal sem glúten, oriundo da África e da Ásia. Por não apresentar glúten em sua constituição, esse cereal mostra-se como uma excelente alternativa de ingrediente para produtos destinados a portadores da doença celíaca (DC). A DC é uma doença autoimune que acomete indivíduos geneticamente predispostos, os tornando intolerantes ao glúten e os impedindo de consumir produtos contendo essa proteína (Araújo et al., 2010).

Não foram encontrados na literatura estudos que desenvolveram formulações de hambúrgueres com adição de farinha de sorgo. Porém, existem trabalhos que formularam hambúrgueres com adição de outros tipos de farinha como: linhaça, maracujá, chia, entre outros.

Com isso, o objetivo do presente estudo foi desenvolver um hambúrguer de carne bovina com adição de diferentes concentrações de farinha de sorgo e avaliar seus atributos tecnológicos e sensoriais.

\section{MATERIAL E MÉTODOS}

\section{OBTENÇÃO DAS MATÉRIAS-PRIMAS}

A farinha de sorgo para a elaboração dos hambúrgueres foi adquirida em estabelecimentos comerciais da cidade de Maringá - PR. Os ingredientes utilizados nas formulações como a gordura suína, gelo, proteínas texturizada de soja, sal, pimenta branca moída e alho em pó foram adquiridos em comércio local da cidade de Umuarama - PR e o glutamato monossódico e o eritorbato de sódio foram doados pela empresa Duas Rodas ${ }^{\circledR}$ de Jaraguá do Sul- Santa Catarina. A carne utilizada para a elaboração dos hambúrgueres foi a alcatra, sendo que a mesma foi moída no estabelecimento na qual foi adquirida.

\section{ELABORAÇÃO DOS HAMBÚRGUERES}

A carne e o toucinho foram moídos em moedores do próprio estabelecimento onde eles foram adquiridos, e posteriormente adicionou-se a água e o sal, para que ocorresse a extração das proteínas miofibrilares. Após conveniente mistura, colocou-se os demais ingredientes. Hidratou-se a proteína texturizada de soja (PTS) em água potável quente antes da sua utilização. Adicionou-se o toucinho e a farinha de sorgo em diferentes proporções, originando quatro 
formulações denominadas F1, F2, F3 e F4, que estão apresentadas na Tabela 1.

Tabela 1. Porcentagem de ingredientes de cada formulação de hambúrguer.

\begin{tabular}{lcccc}
\hline \multirow{2}{*}{ Ingredientes } & \multicolumn{4}{c}{ Formulações (\%) } \\
\cline { 2 - 5 } & F1 & F2 & F3 & F4 \\
\hline Carne bovina (alcatra) & 74,25 & 74,25 & 74,25 & 74,25 \\
Farinha de sorgo & 0,0 & 2,5 & 5,0 & 10,0 \\
Gordura suína (toucinho) & 10,0 & 7,5 & 5,0 & 0,0 \\
Gelo & 8,5 & 8,5 & 8,5 & 8,5 \\
Proteína texturizada de soja & 5,0 & 5,0 & 5,0 & 5,0 \\
Sal & 1,4 & 1,4 & 1,4 & 1,4 \\
Pimenta branca moída & 0,04 & 0,04 & 0,04 & 0,04 \\
Alho em pó & 0,09 & 0,09 & 0,09 & 0,09 \\
Glutamato monossódico & 0,44 & 0,44 & 0,44 & 0,44 \\
Eritorbato de sódio & 0,09 & 0,09 & 0,09 & 0,09 \\
\hline
\end{tabular}

Após a mistura dos ingredientes, deixou-se a massa em repouso sob refrigeração por 20 minutos.

Para a moldagem, pesou-se $90 \mathrm{~g}$ da massa para a produção de cada hambúrguer. Após serem identificados por tratamento, as amostras foram congeladas em freezer vertical sob temperatura de $-18{ }^{\circ} \mathrm{C}$ por 24 horas. Depois os hambúrgueres foram grelhados em chapa aquecida untada com óleo vegetal. Após o grelhamento os hambúrgueres foram utilizados para realização de análises posteriores.

\section{ANÁLISES MICROBIOLÓGICAS}

As formulações elaboradas foram avaliadas microbiologicamente. Vale ressaltar que as análises microbiológicas se realizaram com os hambúrgueres e a carne de preparo em estado cru.

As análises foram realizadas visando a identificação das principais bactérias exigidas pela legislação segundo a RDC $n^{\circ} 12$ de 02 de janeiro de 2001 da ANVISA para produtos cárneos crus, refrigerados ou congelados que são Coliformes a $45^{\circ} \mathrm{C} / \mathrm{g}$ e Salmonella sp.

Todas as análises seguiram as técnicas descritas por American Public Health Association (APHA, 2001).

\section{ANÁLISES FÍSICO-QUíMICAS}

\section{ANÁlise DE UMIDADE}

Para determinar a umidade do hambúrguer cru e cozido, pesou-se de $5 \mathrm{~g}$ da amostra em cápsula de metal, previamente tarada. Colocou-se as 
cápsulas em estufa a $105^{\circ} \mathrm{C}$ por 5 horas, em seguida as cápsulas foram colocadas em dessecadores por 30 minutos e pesadas. Repetiu-se essa operação até peso constante (AOAC, 1997). As análises foram realizadas em triplicata. Para o cálculo realizou-se a seguinte equação:

$\frac{\text { Umidade inicial - Umidade final }}{\text { Umidade inicial }} \times 100$

\section{ANÁLISE DE pH}

Realizou-se a análise de $\mathrm{pH}$ em triplicata e determinou-se por potenciometria com o auxílio de pHmetro digital de bancada (Quimis modelo Q400AS), previamente calibrado com solução tampão de 7 e 4 e inserção na amostra (AOAC, 2000).

\section{ANÁLISE OBJETIVA DE COR}

A avaliação objetiva da cor foi conduzida com o auxílio de um colorímetro portátil (Minolta CR400), seguindo as recomendações sugeridas por Ramos e Gomide (2007). Para o cálculo dos índices de cor, foram estabelecidos pelo sistema CIELAB, em que o valor $L^{*}$ fornece luminosidade, variando do branco $(\mathrm{L}=100)$ ao preto $(\mathrm{L}=0)$, o valor de $\mathrm{a}^{*}$ caracteriza a coloração do vermelho $(+a,+60)$ ao verde $(-a,-60)$, o valor $b^{*}$ indica coloração no intervalo do amarelo $(b+, 60)$ ao azul $(-b,-60)$. Foi realizada a análise em três pontos diferentes.

\section{ANÁlise INSTRUMENTAL DA FORÇA DE CISALHAMENTO}

Para a análise de cisalhamento (textura) dos hambúrgueres utilizouse um texturômetro TA.XT2i (Stable Micro System Inc.) acoplado com lâmina de cisalhamento padrão Warner-Bratzler, calibrado para velocidade de corte de $2 \mathrm{~mm} / \mathrm{s}$, velocidade de retorno de $5 \mathrm{~mm} / \mathrm{s}$ e medida em kgf. As amostras foram submetidas a um teste de corte/cisalhamento usando o trabalho de cisalhamento (kgf), que indica a energia total (trabalho) necessária para o cisalhamento (tenacidade).

\section{CARACTERÍSTICAS DE COZIMENTO}

Após o cozimento, os hambúrgueres foram avaliados quanto ao rendimento de cocção, percentual de encolhimento e percentual de retenção de umidade. 
Determinou-se o rendimento na cocção segundo a metodologia estabelecida por Piñero et al. (2008). Os resultados foram calculados utilizando a equação:

$$
\% \text { Rendimento }=\frac{\text { Peso da amostra cozida }}{\text { Peso da amostra crua }} \times 100
$$

\section{PORCENTAGEM DE ENCOLHIMENTO}

Determinou-se o percentual de encolhimento segundo a metodologia estabelecida por Piñero et al. (2008). Os resultados foram calculados segundo a equação:

$$
\% \text { encolhimento }=\frac{\text { (diâmetro da amostra crua }- \text { diâmtro da amostra cozida }}{\text { diâmetro da amostra crua }} \times 100
$$

\section{PORCENTAGEM DE RETENÇÃO DE UMIDADE}

Determinou-se o percentual de retenção de umidade segundo a metodologia estabelecida por Silva (2013). Os resultados foram obtidos utilizando a equação:

$$
\% \text { umidade }=\frac{(\text { Peso da amostra cozida } \mathrm{x} \% \text { umidade na amostra cozida })}{(\text { Peso da amostra crua } \mathrm{x} \% \text { umidade na amostra crua })} \times 100
$$

\section{TESTE DE ACEITAÇÃO SENSORIAL DOS HAMBÚRGUERES}

Para avaliação da aceitação das formulações dos hambúrgueres, utilizou-se o teste de aceitação por escala hedônica. A pesquisa de análise sensorial foi executada no Laboratório de Análise Sensorial localizado no Bloco B, do Departamento de Tecnologia, da Universidade Estadual de Maringá (UEM), Campus Regional de Umuarama, aprovada conforme o comitê de ética número 86435318.7.0000.0104.

Por meio do teste da escala hedônica, o indivíduo declara o grau de gostar ou de desgostar de um estipulado produto, de modo globalizado ou em associação a um atributo específico. Foi aplicada a escala de 9 pontos, que contém os termos determinados posicionados, entre "gostei muitíssimo" e "desgostei muitíssimo" abrangendo um ponto intermediário com o termo nem gostei; nem desgostei. Realizou-se o teste empregando o painel sensorial de 100 provadores não treinados.

As instruções para a apresentação do produto aos consumidores foram seguidas de acordo com o Instituto Adolfo Lutz (2008). 
ANÁlise estatística

Os resultados obtidos para todas as análises realizadas neste estudo foram submetidos à análise de variância (ANOVA) a 5\% de probabilidade, pelo teste de Tukey, através do software Statistica, versão 7.0.

\section{RESULTADOS E DISCUSSÃO}

\section{ANÁLISES MICROBIOLÓGICAS}

Os dados obtidos para a análise microbiológica da carne bovina e dos hambúrgueres para os quatro tratamentos que estão descritos na Tabela 2, revelaram condições sanitárias satisfatórias do produto de acordo com a Resolução RDC n.12 Agência Nacional da Vigilância Sanitária para consumo humano, possibilitando a carne de ser utilizada para a elaboração do hambúrguer, e desta forma o hambúrguer ser utilizado para a análise sensorial.

Tabela 2. Análise microbiológica da carne bovina in natura e do hambúrguer.

\begin{tabular}{lccc}
\hline Determinações & $\begin{array}{c}\text { Carne Bovina in } \\
\text { natura NMP } / \mathrm{g}\end{array}$ & $\begin{array}{c}\text { Hambúrgueres } \\
\text { (4 tratamentos) } \\
\text { NMP } / \mathrm{g}\end{array}$ & $\begin{array}{c}\text { Padrões Microbiológicos } \\
\text { (Brasil, 2001) }\end{array}$ \\
\hline Salmonella sp $/ 25 \mathrm{~g}$ & Ausente & Ausente & Ausência em $25 \mathrm{~g}$ \\
Coliformes a $45^{\circ} \mathrm{C} / \mathrm{g}$ & $<3$ & $4 \times 10^{2} \mathrm{NMP} / \mathrm{g}$ & $5 \times 10^{2} \mathrm{NMP} / \mathrm{g}$ \\
\hline
\end{tabular}

Observou-se na Tabela 2, para Coliformes a $45^{\circ} \mathrm{C} / \mathrm{g}$, que todas as amostras estão abaixo do máximo preconizado pela legislação vigente.

\section{ANÁLISES FÍSICO-QUÍMICAS}

\section{ANÁLISE DE UMIDADE}

Os valores médios dos teores de umidade e os respectivos desvios padrões avaliados em hambúrgueres de carne bovina crua e submetidos aos tratamentos térmicos estão apresentados na Tabela 3.

Os resultados dos teores de umidade para amostras cruas não apresentaram diferença significativa entre as quatro formulações.

Os teores de umidade para as amostras cruas encontradas neste estudo foram semelhantes aos valores encontrados por Ferrão et al. (2012), em amostras de hambúrgueres bovino in natura formulados com diferentes níveis de extrato de farelo de arroz, cujos valores variaram de 72,24 a 72,60\%. Estes valores são superiores ao encontrado por Borba (2010), em amostras de hambúrgueres bovino cru (60,29\%). 
Tabela 3. Resultados dos teores de umidade de hambúrgueres bovino suplementados com farinha de sorgo nas formas crua e cozido dados em porcentagem (\%).

\begin{tabular}{lcc}
\hline Formulação & Hambúrguer Cru (\%) & Hambúrguer Cozido (\%) \\
\hline F1 & $70,74^{\mathrm{a}} \pm 0,40$ & $57,61^{\mathrm{c}} \pm 0,73$ \\
F2 & $70,69^{\mathrm{a}} \pm 0,38$ & $58,75^{\mathrm{b}} \pm 0,45$ \\
F3 & $70,75^{\mathrm{a}} \pm 0,20$ & $59,52^{\mathrm{b}} \pm 0,55$ \\
F4 & $70,32^{\mathrm{a}} \pm 0,38$ & $63,02^{\mathrm{a}} \pm 0,58$ \\
\hline
\end{tabular}

Médias seguidas de mesma letra minúscula na coluna não diferem entre si pelo teste de Tukey (p<0,05). Onde: F1: (0\% Farinha de Sorgo (FS); 10\% de Gordura Suína (GS)); F2: (2,5\% FS; 7,5\% de GS); F3: (5\% FS; 5\% GS); F4: (10\% FS; 0\% de GS). Os resultados são médias das triplicatas com as respectivas estimativas do desvio padrão.

Os teores de umidade das amostras de hambúrgueres bovino, submetidos ao tratamento térmico por cozimento apresentaram valores que variaram de $63,02 \%$ (F4) a $57,61 \%$ (F1). Onde as formulações 2 e 3 não obtiveram diferença significativa entre si, e a formulação 4 apresentou uma maior umidade em relação aos demais. Os resultados apresentados para o teor de umidade da formulação do hambúrguer cozido levam a supor que a adição de $10 \%$ de farinha de sorgo na formulação F4, contribuiu para o aumento do teor de umidade nestas amostras.

Valores inferiores os observados no presente estudo foram encontrados por Borba (2010) em hambúrguer bovino submetido a diferentes processos de tratamento térmico com valores de 49,96\% para amostras de hambúrgueres submetidos à fritura, 55,77\% para amostras de hambúrguer assado em forno convencional. Mostrando assim que a farinha de sorgo no hambúrguer consegue reter um maior teor de umidade.

\section{ANÁLISE DE pH}

Na Tabela 4 estão apresentados os valores de $\mathrm{pH}$ das formulações dos hambúrgueres de carne bovina crua com adição de farinha de sorgo.

Para a carne, o pH é um importante parâmetro de qualidade já que pode influenciar a cor, a capacidade de retenção de água, a maciez, dentre outros fatores (Geesink et al., 2000).

Tabela 4. Valores dos pH das formulações dos hambúrgueres de carne bovina com adição de farinha de sorgo.

\begin{tabular}{lc}
\hline Formulação & $\mathrm{pH}$ \\
\hline F1 & $5,64^{\mathrm{c}} \pm 0,02$ \\
F2 & $5,65^{\mathrm{c}} \pm 0,01$ \\
F3 & $5,68^{\mathrm{b}} \pm 0,01$ \\
F4 & $5,72^{\mathrm{a}} \pm 0,01$ \\
\hline
\end{tabular}

Médias seguidas de mesma letra minúscula na coluna não diferem entre si pelo teste de Tukey (p<0,05). Onde: F1: (0\% Farinha de Sorgo (FS); 10\% de Gordura Suína (GS)); F2: (2,5\% FS; 7,5\% de GS); F3: (5\% FS; 5\% GS); F4: (10\% FS; 0\% de GS). Os resultados são médias das triplicatas com as respectivas estimativas do desvio padrão. 
Em relação a análise de $\mathrm{pH}$, pode-se observar que a formulação 4 apresentou maior valor, sendo que esta diferiu significativamente das demais formulações. Esse $\mathrm{pH}$ mais elevado pode ser decorrente do $\mathrm{pH}$ da farinha de sorgo que é próximo de 6,3 (Souza et al., 2005), próximo do neutro, então como essa formulação foi utilizada uma maior quantidade dessa farinha, obteve-se um $\mathrm{pH}$ maior.

No trabalho de Melo e Clerici (2013) a adição de farinha desengordurada de gergelim em uma concentração acima de $13 \%$ reduziu o pH. Esse resultado não está de acordo com o presente trabalho que verificou que a adição de farinha de sorgo em concentração de $10 \%$ apresentava maior $\mathrm{pH}$.

\section{ANÁLISE DE COR}

A cor das carnes é um importante atributo de qualidade, pois é um dos primeiros aspectos a serem avaliados pelos consumidores nas gôndolas dos supermercados. É um indício do seu frescor e influencia diretamente o consumidor na decisão final de sua aquisição (Fletcher et al., 2000).

Os resultados da determinação de cor dos hambúrgueres crus com diferentes níveis de adição de farinha de sorgo são apresentados na Tabela 5.

Tabela 5. Análise objetiva de cor do hambúrguer cru de carne bovina com adição de farinha de sorgo.

\begin{tabular}{lccc}
\hline Formulação & $\mathrm{L}^{*}$ & $\mathrm{a}^{*}$ & $\mathrm{~b}^{*}$ \\
\hline F1 & $51,00^{\mathrm{a}} \pm 0,07$ & $7,03^{\mathrm{d}} \pm 0,02$ & $13,95^{\mathrm{b}} \pm 0,02$ \\
F2 & $50,33^{\mathrm{b}} \pm 0,04$ & $8,09^{\mathrm{b}} \pm 0,01$ & $14,80^{\mathrm{a}} \pm 0,02$ \\
F3 & $42,74^{\mathrm{d}} \pm 0,02$ & $7,94^{\mathrm{c}} \pm 0,01$ & $12,88^{\mathrm{c}} \pm 0,02$ \\
F4 & $45,80^{\mathrm{c}} \pm 0,02$ & $8,25^{\mathrm{a}} \pm 0,02$ & $12,02^{\mathrm{d}} \pm 0,01$ \\
\hline
\end{tabular}

Médias seguidas de mesma letra minúscula na coluna não diferem entre si pelo teste de Tukey $(\mathrm{p}<0,05)$. Onde: F1: (0\% Farinha de Sorgo (FS); $10 \%$ de Gordura Suína (GS)); F2: (2,5\% FS; 7,5\% de GS); F3: (5\% FS; 5\% GS); F4: (10\% FS; 0\% de GS). Os resultados são médias das triplicatas com as respectivas estimativas do desvio padrão.

Os valores de luminosidade $\left(\mathrm{L}^{*}\right)$ apresentaram diferenças significativas $(p>0,05)$ entre todas as formulações analisadas. Tais resultados demonstraram que os níveis de substituição da farinha de sorgo selecionados para este estudo impactaram neste parâmetro $\left(\mathrm{L}^{*}\right) \mathrm{de}$ avaliação de cor objetiva, sendo que as formulações F3 e F4 apresentaram menores valores de luminosidade quando comparados com a amostra controle (F1). A diferença na luminosidade pode estar relacionada com diferenças no teor de água e sua mobilidade em sentido à superfície, capacidade de retenção de água, estrutura muscular e pH (Araújo, 2017). Como a farinha de sorgo adicionada as formulações possuíam coloração escura (marrom), era esperada esta diferença entre as amostras. Além de que o valor de $L^{*}$ do tratamento com elevada quantidade de gordura (F1) 
apresentou-se maior, indicando assim, que a gordura torna o produto mais pálido, já que quanto maior o valor de L, mais clara será a amostra.

Em relação ao parâmetro ( $\mathrm{a}^{*}$ ) que tende a uma coloração do vermelho ao verde, todas as formulações diferiram-se significativamente entre si, sendo que a F1 apresentou menor intensidade desta coloração. Isso pode ser explicado devido a formulação F1 apresentar maior proporção de toucinho.

Em relação ao parâmetro b*, que tende a uma coloração do amarelo ao azul, foi observado uma diminuição nos valores para os tratamentos com maiores níveis de farinha de sorgo, sendo que segundo a escala para o parâmetro $b^{*}$, isso era esperado, pois valores maiores (tendendo ao positivo) apresentam coloração tendendo ao amarelo (mais clara), o que foi observado na amostra controle e na amostra F2 que apresentava menor teor de farinha de sorgo.

\section{ANÁlise INSTRUMENTAL DA FORÇA DE CISALHAMENTO}

Na Tabela 6, são apresentados os valores de força de cisalhamento para os hambúrgueres grelhados elaborados neste trabalho.

Tabela 6. Força de cisalhamento (kgf/s) para as diferentes formulações de hambúrgueres grelhados.

\begin{tabular}{lc}
\hline Formulação & Força $(\mathrm{kgf} / \mathrm{s})$ \\
\hline F1 & $1,80^{\mathrm{a} \pm 0,07}$ \\
F2 & $1,82^{\mathrm{a} \pm 0,08}$ \\
F3 & $1,85^{\mathrm{a} \pm 0,22}$ \\
F4 & $1,86^{\mathrm{a} \pm 0,24}$ \\
\hline
\end{tabular}

Médias seguidas de mesma letra minúscula na coluna não diferem entre si pelo teste de Tukey $(\mathrm{p}<0,05)$. Onde: F1: (0\% Farinha de Sorgo (FS); $10 \%$ de Gordura Suína (GS)); F2: (2,5\% FS; 7,5\% de GS); F3: (5\% FS; 5\% GS); F4: (10\% FS; 0\% de GS). Os resultados são médias das triplicatas com as respectivas estimativas do desvio padrão.

Os valores obtidos nesse trabalho variaram de 1,80 a 1,86 kgf/s, não sendo observada diferença significativa entre as amostras $(p<0,05)$.

Uma vez que ocorrem mudanças (coloração, textura, sabor) nos produtos cárneos durante e após o cozimento alterando suas características, a força de cisalhamento, isto é, a força necessária para cortar a carne, pode ser usada como parâmetros de avaliação de qualidade sensorial. A percepção desta dureza baseia-se na apreciação visual e táctil, resistência, facilidade de fragmentação e formação de resíduos da mastigação (Ordòñez, 2005). 
Na Tabela 7 estão apresentados os valores de rendimento de cocção, encolhimento e retenção de umidade.

Tabela 7. Porcentagem de rendimento de cocção, encolhimento e retenção de umidade das formulações de hambúrgueres de carne bovina com adição de farinha de sorgo.

\begin{tabular}{lccc}
\hline Formulação & $\begin{array}{c}\text { Rendimento de } \\
\text { Coç̧̃̃o (\%) }\end{array}$ & Encolhimento (\%) & $\begin{array}{c}\text { Retenção de } \\
\text { Umidade (\%) }\end{array}$ \\
\hline F1 & $65,51^{\mathrm{d}} \pm 0,25$ & $23,81^{\mathrm{a}} \pm 0,27$ & $70,60^{\mathrm{d}} \pm 0,01$ \\
F2 & $76,86^{\mathrm{c}} \pm 0,20$ & $18,04^{\mathrm{b}} \pm 0,37$ & $88,02^{\mathrm{b}} \pm 0,01$ \\
F3 & $82,99^{\mathrm{b}} \pm 0,22$ & $13,62^{\mathrm{c}} \pm 0,35$ & $74,56^{\mathrm{c}} \pm 0,02$ \\
F4 & $89,15^{\mathrm{a}} \pm 0,15$ & $9,48^{\mathrm{d}} \pm 0,33$ & $92,66^{\mathrm{a}} \pm 0,01$ \\
\hline
\end{tabular}

Médias seguidas de mesma letra minúscula na coluna não diferem entre si pelo teste de Tukey $(\mathrm{p}<0,05)$. Onde: F1: (0\% Farinha de Sorgo (FS); 10\% de Gordura Suína (GS)); F2: (2,5\% FS; 7,5\% de GS); F3: (5\% FS; 5\% GS); F4: (10\% FS; 0\% de GS). Os resultados são médias das triplicatas com as respectivas estimativas do desvio padrão.

No rendimento de cocção todas as formulações apresentaram diferença significativa entre si, a formulação 4 apresentou um rendimento de cocção elevado em relação as outras amostras, portanto, com menor perda de peso do hambúrguer.

Isso está relacionado com o parâmetro de retenção de umidade calculado para os hambúrgueres avaliados, sendo que a formulação 4 apresentou maior retenção de umidade durante o processo de grelhamento, esses resultados demonstram que a farinha de sorgo apresentou habilidade em reter água no produto durante o processo de cozimento, este fator pode ser decorrente do alto teor de fibras (18\%) que a farinha de sorgo possui. Seabra et al. (2002) observou também uma maior capacidade de reter umidade quando empregou farinha de aveia em produtos cárneos, com uma taxa de retenção de $78 \%$.

O encolhimento é causado principalmente pela desnaturação de proteínas durante o cozimento e parcialmente pela evaporação de água e fusão das gorduras da carne (Choi et al. 2009). De acordo com os resultados apresentados todas as formulações apresentaram diferença significativa entre si e a formulação 4 foi a que apresentou menor encolhimento. Conforme a adição da farinha na formulação ocorreu uma redução gradativa na porcentagem de encolhimento variando de $23,81 \%$ sem adição de farinha de sorgo até 9,48\% com adição de $10 \%$ de farinha de sorgo. Estes fatores podem ser as causas da variabilidade dos resultados encontrados neste estudo para este parâmetro.

\section{TESTE DE ACEITAÇÃO SENSORIAL DOS HAMBÚRGUERES}

Participaram da pesquisa 100 voluntários não treinados, da comunidade acadêmica da Universidade Estadual de Maringá (UEM- 
CTC), envolvendo estudantes, professores e funcionários, onde 70,87\% eram do sexo feminino e $29,13 \%$ eram do sexo masculino.

A Tabela 8 apresenta as médias encontradas para os atributos avaliados (avaliação global, cor, textura, sabor e intenção de compra) para hambúrgueres elaborados com carne bovina adicionados de farinha de sorgo.

Tabela 8. Médias dos atributos avaliados durante a análise sensorial para cada formulação de hambúrguer.

\begin{tabular}{lccccc}
\hline Formulação & $\begin{array}{c}\text { Avaliação } \\
\text { Global }\end{array}$ & Cor & Textura & Sabor & $\begin{array}{c}\text { Intenção de } \\
\text { Compra }\end{array}$ \\
\hline F1 & $6,58^{\mathrm{c} \pm 0,19}$ & $6,50^{\mathrm{b} \pm 0,17}$ & $7,64^{\mathrm{b} \pm 0,21}$ & $7,83^{\mathrm{b} \pm 0,23}$ & $1,88^{\mathrm{a} \pm 0,96}$ \\
F2 & $8,02^{\mathrm{a} \pm} 0,35$ & $7,73^{\mathrm{a} \pm} 0,29$ & $8,06^{\mathrm{a} \pm 0,27}$ & $8,20^{\mathrm{a} \pm 0,26}$ & $1,63^{\mathrm{a} \pm 0,87}$ \\
F3 & $7,79^{\mathrm{a} \pm 0,22}$ & $7,79^{\mathrm{a} \pm 0,26}$ & $7,68^{\mathrm{b} \pm 0,40}$ & $7,89^{\mathrm{b} \pm 0,35}$ & $1,87^{\mathrm{a} \pm 0,87}$ \\
F4 & $7,60^{\mathrm{b} \pm 0,13}$ & $7,75^{\mathrm{a} \pm 0,16}$ & $7,40^{\mathrm{c} \pm 0,11}$ & $7,30^{\mathrm{c} \pm 0,17}$ & $2,20^{\mathrm{a} \pm 1,20}$
\end{tabular}

Médias seguidas de mesma letra minúscula na coluna não diferem entre si pelo teste de Tukey (p<0,05). Onde: F1: (0\% Farinha de Sorgo (FS); 10\% de Gordura Suína (GS)); F2: (2,5\% FS; 7,5\% de GS); F3: (5\% FS; 5\% GS); F4: (10\% FS; 0\% de GS). Os resultados são médias das triplicatas com as res Para o atributo avaliação global as formulações 2 e 3 não tiveram diferença significativa entre si, apresentando a maior pontuação, 8,02 e 7,79 respectivamente. Já as formulações 1 e 4 diferiram significativamente das outras amostras.

Para o atributo cor as formulações 2, 3 e 4 com adição de farinha de sorgo não diferiram entre si, exceto o controle (formulação 1) havendo diferença significativa $(\mathrm{p}<0,05)$ entre as outras amostras, apresentando uma média inferior aos demais $(6,50)$. Esta diferença pode ter ocorrido devido a coloração da formulação 1 ser mais clara em relação as formulações 2 , 3 e 4 .

$\mathrm{Na}$ avaliação do atributo textura, as formulações 1 e 3 não tiveram diferença significativa, já nas formulações 2 e 4 tiveram diferença significativa $(p<0,05)$ entre as amostras, sendo a formulação 2 com maior pontuação $(8,06)$ e a formulação 4 com a menor pontuação $(7,40)$, essa pontuação mais baixa pode ser decorrente da proporção de farinha utilizado, pois a farinha deixou o hambúrguer com uma textura mais rígida, assim o tornando levemente mais seco em relação as outras formulações, segundo os provadores.

Para o atributo sabor, as formulações 1 e 3 não apresentaram diferença significativa entre as amostras, já entre as formulações 2 e 4 houve diferença significativa $(\mathrm{p}<0,05)$ dentre as outras amostras, sendo a formulação 2 com maior pontuação $(8,20)$.

Com o apresentado é possível observar que na intenção de compra as formulações não diferiram significativamente entre si, sendo a 
formulação 2 com melhor intenção de compra $(1,88)$ e a formulação 4 com menor intenção de compra $(2,20)$.

Diante disso, observou-se que houve boa aceitação das quatro formulações de hambúrgueres, independentemente do seu alto teor de farinha de sorgo na última formulação.

\section{CONCLUSÃO}

A adição de farinha de sorgo em substituição à gordura suína em hambúrgueres de carne bovina demonstrou melhores características quando comparado com hambúrguer padrão (sem adição de farinha de sorgo). Observou-se que a formulação 4 com adição de $10 \%$ de farinha de sorgo e $0 \%$ de toucinho suíno foi a formulação que maior umidade (F4:63,02\%), mostrando melhor rendimento do produto, para as características de cozimento, apresentando maior capacidade de retenção de umidade (F4:92,66\%), com isso maior rendimento (F4:89,15\%) e menor encolhimento (9,48\%).

A análise sensorial apresentou boa aceitabilidade para todas as formulações, porém a formulação 2 revelou-se a melhor em todos os aspectos (avaliação global, cor, textura, sabor), e esta formulação também foi a que apresentou maior intenção de compra pelos provadores.

Isso demonstra que com a boa aceitação sensorial e por ser um produto novo, que ainda não existe comercialmente, seria viável sua produção e comercialização. Sendo a farinha também uma forma de melhorar o potencial nutricional, contribuindo para melhor saúde do consumidor.

\section{REFERÊNCIAS}

APHA, American Public Health Association, Committee on Microbiological Methods for Foods. 2001. Compendium of methods for the microbiological examination of foods (4a ed.). Washington, DC.

Araújo, B. S. 2017. Processamento e caracterização física e química de hambúrgueres formulados com pectina do maracujá amarelo. Dissertação (Universidade Estadual do Sudoeste da Bahia - UESB - Engenharia e Ciência de Alimentos, Itapetinga, BA).

Araújo, H. M. C., Araujo, W.M.C., Botelho, R.B.A., \& Zandonadi, R.P. 2010. Doença celíaca, hábitos e práticas alimentares e qualidade de vida. Revista de Nutrição, 23(3), 467-472.

AOAC, Association of Official Analytical Chemistry. 1997. Official methods of analysis (16a ed). Washington, DC: AOAC International.

AOAC, Association of Official Analytical Chemistry. 2000. Official methods of analysis (16a ed). Washington, DC: AOAC International. 
Borba, C.M., Oliveira, V. R., Montenegro, K. R., Hertz, P. F., Venzke, J. G. 2013. Avaliação físico química de hambúrguer de carne bovina e de frango submetidos a diferentes processamento térmicos. Brazilian Journal of Food Nutrition, 24(1), 21-27.

Brasil, Ministério da Saúde, Agência Nacional de Vigilância Sanitária (ANVISA). 2001. Resolução (RDC) $\mathrm{n}^{\circ}$ 12: regulamento técnico sobre padrões microbiológicos para alimentos, Brasília, DF.

Choi, Y. S., Choi, J. H., Han, D. J., Kim, H. Y., Lee, M. A., Kim, H. W., Jeong, J. Y., \& Kim, C. J. 2009. Characteristics of low-fat meat emulsion systems with pork fat replaced by vegetable oils and rice bran fiber. Meat Science, 82(2), 266-271.

Ferrão, T.S., Macagnan, F.T., Brum, F.B. \& Silva, L.P. 2012. Aplicação de extrato de farelo de arroz como antioxidante em hambúrguer bovino. Ciencia e Tecnologia de Alimentos, 28, 551-557.

Fletcher, D. L., Qiao, M., \& Smith, D.P. 2000. The relationship of raw broiler breast meat color and pH to cooked meat color and pH. Poultry Science, 79, 784-788.

Geesink, G. H., Bekhit, A. D., \& Bickerstaffe, R. 2000. Rigor temperature and meat quality characteristics of lamb longissimus muscle. Meat Science, 78, 2842 - 2848.

IAL, Instituto Adolfo Lutz. 2008. Métodos químicos e físicos para análise de alimentos (3a ed.). São Paulo, SP: Instituto Adolfo Lutz.

Melo, L.S.M., \& Clerici, M.T.P.S. 2013. Desenvolvimento e avaliação tecnológica, sensorial e físico-química de produto cárneo, tipo hambúrguer, com substituição de gordura por farinha desengordurada de gergelim. Alimentos e Nutrição, 24(4), 361-368.

Ordòñez, A. O. 2005. Tecnologia de alimentos (v.2, cap. 12). São Paulo, SP: Artmed.

Piñero, M.P., Parra, K., Huerta-Leidenz, N., Arenas de Moreno, L., Ferrer, M.; Araujo, S.; \& Barboza, Y. 2008. Effect of oat's soluble fibre (ß-glucan) as a fat replacer on physical, chemical, microbiological and sensory properties of low-fat beef patties. Meat Science, 80, 675-680.

Ramos, E. M., \& Gomide, L. A. M. 2007. Avaliação da qualidade de carnes: fundamentos e metodologias. Viçosa, MG: UFV.

Rodrigues, F. J. 2008. Desenvolvendo Alimentos com Alto Teor de Gordura. Food Ingredients Brasil, 5, 48-68.

Seabra, L. M .J. 2002. Fécula de mandioca e farinha de aveia como substitutos de gordura na formulação de hambúrgueres de carne ovina. Ciência e Tecnologia dos Alimentos, 22(3), 224-248.

Silva, C. E. 2013. 2013. Elaboração e avaliação de hambúrgueres de carne bovina com substituições de toucinho por farina de linhaça. Dissertação (Universidade Tecnológica Federal do Paraná - UTFPR, Londrima, PR).

Souza, C. C., Dantas, J. P., Silva, S. M., Souza, V. C., Almeida, F. A., \& Silva, L. E. 2005. Produtividade do Sorgo granífero cv. sacarino e qualidade de produtos formulados isoladamente ou combinados ao caldo de cana-de-açúcar. Ciência Tecnológica Alimentar, 3, 287-293.

Waniska, R. D, \& Rooney, L. W. 2010. Structure and chemistry of the sorghum caryopsis. In: W. SMITH e R. A. FREDERIKSEN (Ed.). Sorghum: production, agronomy, chemistry and utilization. New York, NY: Wiley \& Sons. 


\section{MINICURRÍCULO}

ANA BEATRIZ COSTA FERNANDES Engenheira de Alimentos, graduada pela Universidade Estadual de Maringá (UEM), tem experiência em indústria de alimentos tendo atuado em desenvolvimento de novos produtos; treinamento em boas práticas de fabricação; acompanhamento de produção; controle de qualidade; análises físico-químicas e microbiológicas de matérias-primas e produtos acabados; criação de DAC'S e POP'S. Realizou pesquisa científica na área de Obtenção e Aplicação de Leveduras Autolisadas e realizou pesquisa científica na área de Desidratação Osmótica da Manga e fez TCC em Elaboração de Hambúrguer de Carne Bovina com Adição de Farinha de Sorgo. Atualmente cursa Mestrado em Engenharia de Alimentos pela UEM.

SANDRIANE PIZATO Possui graduação em Tecnologia de Alimentos (Industrialização de Carnes) pela Universidade Tecnológica Federal do Paraná (2008). Possui mestrado (2011) e doutorado (2015) em Engenharia e Ciência de Alimentos pela Universidade Federal de Rio Grande. É revisora de periódicos nacionais e internacionais de importante relevância. Tem experiência na área de Ciência e Tecnologia de Alimentos e Bioprocessos, com ênfase em Avaliação e controle de qualidade de alimentos e bioprodutos, atuando principalmente nos seguintes temas: carnes, frango, pescado, frutas e hortaliças, microbiologia, qualidade, filmes, resíduos de pescado, fermentação, Lactobacillus, ácido lático. Realizou doutorado sanduíche na University Applied Sciences Bremerhaven (Hochschule Bremerhaven) juntamente com o Instituto BIBIS ( Biological Information Systems) e TTZ (Technology Transfer Centre) em Bremerhaven na Alemanha, por meio do Programa Institucional de Bolsas de Doutorado Sanduíche no Exterior (PDSE). Foi professora substituta no Instituto Federal de Santa Catarina - Campus São Miguel DOeste, onde ministrou aulas para o curso de Técnico em Agroindústria no ano de 2015-2016. Foi Pós Doutoranda no Laboratório de Bioengenharia da Universidade Federal da Grande Dourados - UFGD - MS. Atuou como professora colaboradora na Universidade Estadual de Maringá - Campus Umuarama, ministrando aulas para os cursos de Engenharia e Tecnologia de Alimentos entre 2017-2018. 